\title{
O ALÇAMENTO DAS VOGAIS MÉDIAS PRETÔNICAS /E/ E /O/ SEM MOTIVAÇÃO APARENTE: UM ESTUDO EM TEMPO REAL
}

\author{
THE RISING OF THE MIDDLE UNSTRESSED VOWELS /E/ \\ AND /O/ WITHOUT APPARENT MOTIVATION: A STUDY IN \\ REAL TIME
}

\author{
Valéria Neto de Oliveira Monaretto \\ Universidade Federal do Rio Grande do Sul, Porto Alegre, RS, Brasil
}

\begin{abstract}
Resumo: Este texto trata de contribuir para a investigação do alçamento de vogais pretônicas, estudado pioneiramente por Bisol (1981). Examinar-se-á o alçamento sem motivação aparente, na fala do português brasileiro, por meio de resultados obtidos em doze entrevistas com indivíduos de Porto Alegre, RS, Brasil, realizadas em dois momentos distintos: em 1970 e em 2000. O primeiro corpus pertence ao Projeto NURC e o segundo, ao Projeto VARSUL. A análise de dados é do tipo painel em tempo real (LABOV, 1994), através do qual se compara o comportamento e a mudança linguística da mesma pessoa com o passar dos anos.

Palavras-chave: Vogais Pretônicas; Alçamento; Mudança Linguística; Análise em Tempo Real.
\end{abstract}

Abstract: This text aims to contribute to the investigation of the rising of pretonic vowels, studied pioneered by Bisol (1981). It will examine the raising without apparent motivation in speaking Brazilian Portuguese, using results of twelve interviews of individuals from Porto Alegre, RS, Brazil, performed at two different times: in 1970 and in 2000. The first corpus belongs to the Project NURC, and the second one to the Project VARSUL. Data analysis is of real-time dashboard type (LABOV, 1994), which compares the behavior and language change of the same person over the years.

Keywords: Pretonic vowels; Vowel Raising; Linguistic Change; Analysis in Real Time.

\section{Introdução}

O estudo do alçamento das vogais médias /e, o/ em posição pretônica, como regra variável, foi inicialmente realizado por Bisol, em ocasião de sua Tese de Doutorado (1981) sobre a variedade da língua falada no Rio Grande do Sul. Desde então, surgiram inúmeros trabalhos descritivos sobre esse fenômeno percebido na fala do português brasileiro, trabalhos esses que, por vezes, corroboravam os condicionamentos linguísticos e sociais estudados pela pesquisadora. Destacam-se pelo pioneirismo de estudo desse fenômeno em cada região, os trabalhos de Callou e Leite (1986), sobre a norma culta do Rio de Janeiro; o de Viegas (1987), em Belo Horizonte; o de Silva (1989), sobre a fala de Salvador (Bahia) e o de Castro (1990), em Juiz de Fora (Minas Gerais), entre outros.

O alçamento, chamado também de alteamento ou elevação, refere-se à projeção da língua em direção à parte superior, ou mais alta, da cavidade 
bucal, ao realizar-se uma vogal. É o caso de uma vogal média alta /e, o/ que se projeta para $[i, u]$, respectivamente. A distinção entre alta e baixa, em posição átona, tende a ser reduzida pela neutralização, que tem por consequência a perda do traço que distingue os fonemas.

Segundo Bisol (2010, p. 67), "a variação da pretônica, uma das peculiaridades do português do Brasil, é o reflexo de uma regra muito antiga, oriunda do latim do século IV d. C. e que caracterizou o português quinhentista". A redução da pauta pretônica de cinco vogais para três, segundo a autora, deve ter ocorrido em fins do século XVIII ou no começo do XIX.

$\mathrm{O}$ dialeto gaúcho classifica-se entre aqueles que apresentam esse fenômeno moderadamente. Essa variedade revela a particularidade de preservar a vogal média pretônica por estar em uma região de situação de contato do italiano e do alemão, dos imigrantes, e do espanhol, pelas cidades limítrofes (BISOL, 1981).

O estudo da harmonia vocálica de vogais pretônicas, feito por Bisol (1981), revelou um outro tipo de alteamento, sobre o qual não se aplica, como desencadeador da regra, um dos fatores condicionadores mais relevantes da harmonia: a presença de vogal alta na palavra. Casos de alçamento pareciam aplicar-se variavelmente, na fala do português gaúcho, em palavras como $\mathrm{m}[\mathrm{ol}]$ eque $\sim \mathrm{m}[\mathrm{u}]$ leque e $\mathrm{p}[\mathrm{e}]$ gada $\sim \mathrm{p}[\mathrm{i}]$ gada, por exemplo. Entretanto, o gatilho para sua aplicação não era claro.

Bisol voltou a estudar esse assunto, junto a seus orientandos, anos mais tarde. A dúvida que pairava era como enquadrar esse comportamento variável de pretônica nos termos de uma regra variável, de acordo com Labov, se não havia claramente um condicionador linguístico.

Diante do comportamento instável das vogais pretônicas sem motivação aparente no português brasileiro, propõe-se, neste trabalho, contribuir com novos dados de fala. Tratar-se-á de estudar, em uma amostra específica, o alçamento de vogais em contextos em que não há vogal alta nas sílabas seguintes à pretônica, como ocorre em bulacha por bolacha e em piqueno por pequeno, por exemplo, excetuando-se os casos em que a vogal média for seguida por sibilante (espanta) e por nasal (enxada). Este estudo analisará uma amostra de fala de indivíduos recontatados cerca de trinta anos depois. Trata-se de um estudo em tempo real do tipo painel (LABOV, 1994), cujo primeiro corpus pertence ao Projeto Norma Urbana Culta (NURC), de Porto Alegre, e o segundo, ao Projeto Variação Linguística no Sul do País (VARSUL). 


\section{A Regra Variável do Alçamento de Vogais Médias Pretônicas no Português Brasileiro}

As vogais médias pretônicas do português brasileiro sofrem, desde muito tempo, um processo variável em que /e/e /o/ alternam-se entre os sons $[\mathrm{e}] \sim[\mathrm{i}]$ e $[\mathrm{o}] \sim[\mathrm{u}]$, respectivamente em três situações:

\section{(1) Casos de Alçamento de Vogais Médias Fechadas}

a) quando precedem vogais altas na sílaba adjacente (menino, coruja);

b) quando o /e/ inicial precede sibilante /s/ e nasal (espada, enxada);

c) quando não há as duas situações a e $\underline{b}$ (pequeno, tomate).

O primeiro caso (1a) é chamado de harmonia vocálica. É um processo de desligamento de traços de abertura da vogal média, seguido por um preenchimento de traços de abertura da vogal seguinte (BISOL, 1981). A segunda situação (1b) envolve um alto índice de elevação (cerca de 90\%), merecendo ser estudada à parte, segundo Bisol (1981), por apresentar princípios que regem a elevação da vogal inicial diferentes da elevação da vogal pretônica. Battisti (1993) analisa especificamente esse caso, excluído por Bisol, concluindo que se trata de uma regra em vias de se tornar categórica.

Por último, o terceiro (1c) é um caso em que não se encaixa nos dois anteriores e aparentemente não recebe nenhuma influência fonética/fonológica. Por isso, é denominado de sem motivação aparente.

A harmonia e os dois outros alçamentos são formalmente diferentes na Fonologia. A harmonia é um caso de assimilação, em que há um espraiamento de traço. $\mathrm{O}$ alçamento é um caso de neutralização, em que há um desligamento de traços de abertura e de preenchimento de outros por default (BISOL, 2010).

A harmonia vocálica, como fenômeno variável, foi estudada pioneiramente por Bisol, utilizando-se de amostra de fala coletada no Rio Grande do Sul, em 1978, para fins de seu doutoramento. Desde aí, inúmeros trabalhos foram realizados no Brasil com a tônica de se verificar o comportamento variável de uma regra, que se mostra antiga e estável no português brasileiro. Os estudos apontam para a vogal alta como gatilho para a regra de alçamento da vogal média pretônica, na situação de harmonia vocálica.

O processo de harmonia também se faz presente entre vogais médias abertas, como é o caso da variedade do português brasileiro do norte e nordeste. Cardoso (1999) e Nascimento Silva (2009), dentre outros, registram a harmonia entre vogais médias abertas com vogais $/ \varepsilon, \mathrm{o} / \mathrm{em}$ palavras como elétrica, melhor, jornal, forró, por exemplo, onde a pretônica é realizada 
como média aberta. Esse tipo de variação inexiste na fala do Sul e Sudeste do País.

A elevação, em palavras com a vogal alta em sufixos (-1́ssimo, -inho, -zinho), é tratada diferentemente por Bisol (1981), por entender que certos sufixos têm a propriedade de preservar o acento. Por se posicionarem em fronteira de palavra, bloqueiam a regra de harmonia, que se dá no nível da palavra.

A situação de elevação de 1c abrange contextos variados: em início de palavra ([e]levador [i]levador); no interior de palavra (ac[o]ntecer $\sim \mathrm{ac}[\mathrm{u}]$ ntecer); em hiato (t[e]atro t[i]atro); em sílaba leve ou pesada (pensando/pesado). Os contextos fonológicos precedentes e seguintes à vogal alvo também são comumente analisados em trabalhos sobre o assunto, atribuindo-se papel condicionador às vogais dorsais (quebrado, governo); às labiais precedentes (pelado, boneca) e às vogais seguintes palatais (senhora, sonhar).

Os possíveis condicionadores para o alçamento de vogais médias em palavras em que não há vogal alta /u, i/ não são claros; todavia, corroboram sua terminologia como sem motivação. A discussão sobre essa aparente regra variável tem girado em duas posições originadas pela controversa neogramática/difusão lexical (LABOV, 1981): o condicionamento fonético e/ou o lexical.

Bisol (2010, p. 78) reexamina esse tipo de elevação vocálica, comparando pesquisas variacionistas sobre a fala do Sul do Brasil, assumindo que o fenômeno não se trata de uma regra variável com condicionamento específico, mas de um caso de "expansão pelo léxico por onde se estende via grupos de palavras com uma base comum". Para a autora, o alçamento está mais adiantado com a vogal /o/do que com /e/e ocorre em palavras com uma base em comum. Assim, grupos nominais, verbais e algumas palavras isoladas com vogais alçadas vêm crescendo ao longo da história.

\section{O Alçamento Sem Motivação Aparente em Tempo Real: contribuições de uma nova pesquisa ${ }^{1}$}

Diante das considerações de Bisol de que mais argumentos ainda são necessários para se posicionar a favor de que exista algum condicionador fonético para o alçamento de pretônicas sem motivação aparente e de que resultados de pesquisas apontem para o papel da analogia no amparo da

\footnotetext{
1 Agradeço aos seguintes bolsistas de iniciação científica pela contribuição na coleta e codificação desses dados: Felipe Silveira, Tess Simas e, em especial, pelo envolvimento por mais tempo, Melissa Ferreira Osterlund.
} 
proposta difusionista, este trabalho procura contribuir para o estudo do fenômeno por meio de uma análise de amostras em tempo real.

O estudo da mudança linguística em tempo real é uma estratégia de análise que pode fornecer evidências mais seguras acerca da mudança linguística. Postula-se, nesse tipo de investigação, que a trajetória do comportamento linguístico do indivíduo, ao longo da vida, pode ser diferente da mudança gradual em toda a comunidade (LABOV, 1994).

Há o estudo de painel, em que se compara a fala das mesmas pessoas ao longo dos anos, e o estudo de tendências, que abrange diferentes indivíduos. Este trabalho traz resultados a partir do recontato com 12 indivíduos do Projeto NURC, cerca de 30 anos depois, cuja amostra denominamos de 1970. O recontato desses indivíduos foi realizado pelo Projeto VARSUL, no início do ano 2000, como amostra agregada ao Projeto. Esses informantes têm curso superior e são residentes de Porto Alegre.

Os informantes estão distribuídos por sexo, dentro das seguintes faixas etárias, totalizando sete homens e cinco mulheres: a) 26 a 38 anos - três homens e duas mulheres; b) 39 a 46 anos - dois homens e duas mulheres; c) 47 a 58 anos - quatro homens e duas mulheres; d) 59 a 84 anos - cinco homens e quatro mulheres. A idade de cada informante nas duas coletas, bem como o período de intervalo entre as duas gravações é a que segue:

(2) Idade do informante segundo as duas amostras (1970 e 2000) e intervalo de tempo

\begin{tabular}{|l|l|l|l|}
\hline \multicolumn{1}{|c|}{ Informante } & \multicolumn{1}{|c|}{ Idade em 1970 } & Idade em 2000 & \multicolumn{1}{|c|}{$\begin{array}{c}\text { Intervalo de } \\
\text { Tempo do } \\
\text { Recontato }\end{array}$} \\
\hline A (homem) & 26 anos & 53 anos & 27 anos \\
\hline B (homem) & 28 anos & 55 anos & 27 anos \\
\hline C (homem) & 33 anos & 60 anos & 27 anos \\
\hline D (homem) & 43 anos & 80 anos & 37 anos \\
\hline E (homem) & 45 anos & 72 anos & 27 anos \\
\hline F (homem) & 47 anos & 74 anos & 27 anos \\
\hline G (homem) & 50 anos & 77 anos & 27 anos \\
\hline H (mulher) & 26 anos & 53 anos & 27 anos \\
\hline I (mulher) & 38 anos & 65 anos & 27 anos \\
\hline J (mulher) & 40 anos & 66 anos & 26 anos \\
\hline K (mulher) & 40 anos & 67 anos & 27 anos \\
\hline L (mulher) & 58 anos & 85 anos & 27 anos \\
\hline
\end{tabular}


A metodologia de análise de dados segue pressupostos do estudo da regra variável de Labov (1972) e de Sankoff (1988). Os dados obtidos foram submetidos ao exame estatístico pelo pacote de programas VARBRUL, na versão Goldvarb 3.0.

As variáveis linguísticas controladas foram distância da sílaba tônica, tipo de sílaba, altura da vogal da sílaba precedente e seguinte; posição da pretônica; nasalidade; contexto fonológico precedente e seguinte; posição morfológica da vogal alvo; classe gramatical da palavra. As variáveis sociais examinadas foram sexo, idade, informante e amostra.

Em relação às vogais /e/ e /o/, os resultados obtidos podem ser visualizados na Tabela 1 .

Tabela 1 - Resultados de alçamento em dois períodos de tempo

\begin{tabular}{l|l|l|l|l|l|l}
\hline & \multicolumn{3}{|c|}{ Vogal /e/ } & \multicolumn{3}{c}{ Vogal /o/ } \\
\hline Amostras & Aplic./Total & $\%$ & $\begin{array}{l}\text { Peso } \\
\text { Relativo }\end{array}$ & Aplic./Total & $\%$ & $\begin{array}{l}\text { Peso } \\
\text { Relativo }\end{array}$ \\
\hline $1970 / 2000$ & $110 / 1335$ & 8,2 & -- & $160 / 1224$ & 13,1 & -- \\
\hline 1970 & $47 / 632$ & 7,4 & .51 & $77 / 574$ & 13,4 & .56 \\
\hline 2000 & $63 / 703$ & 9 & .49 & $83 / 650$ & 12,8 & .45 \\
\hline
\end{tabular}

Fonte: Da autora

Os resultados expressos na Tabela 1 confirmam as expectativas para a vogal /o/, em termos de frequência absoluta, por apresentar mais contextos de aplicação para o alçamento. Em contrapartida, se comparado o desenvolvimento de um período para outro, observa-se um leve crescimento para a vogal /e/ e um pequeno decréscimo, para a vogal /o/, diferença pequena, que pode ser atribuída ao informante e ao tipo de entrevista, em cada amostra. Em todo caso, a regra de aplicação é baixa e se mantém, de certa forma, estável, em termos numéricos.

O comportamento de cada informante, no passar do tempo, também parece não se alterar significativamente na maior parte dos indivíduos, conforme pode ser visto no Gráfico 1. 


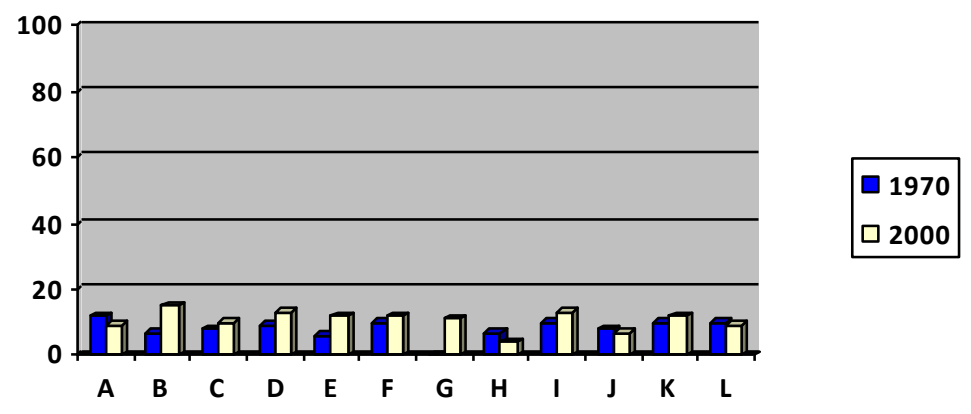

Gráfico 1 - Frequência de alçamento pretônico conforme indivíduo e amostra Fonte: Da autora

Com exceção do informante homem $G$, que parece adquirir o alçamento mais tarde em sua vida, e os informantes A, H, J (homem e mulheres), os demais aumentam seus percentuais de aplicação da regra com o tempo. Os indivíduos com mais idade, nas duas amostras, ao tornarem-se mais velhos, parecem utilizar mais o alçamento, o que pode ser observado no Gráfico 2, em que os informantes estão agrupados por faixa etária e sexo, com escala reduzida para se poder observar melhor a diferença entre as faixas etárias.

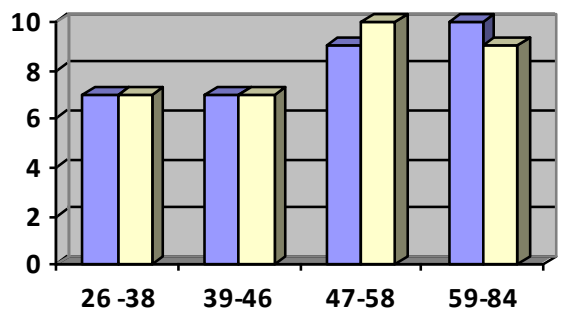

\section{$\square$ Homem \\ Mulher}

Gráfico 2 - Alçamento por faixa etária e sexo conforme amostra Fonte: Da autora

Curioso é o alçamento segundo o sexo no passar dos anos, cujo comportamento é o oposto conforme o período, como pode ser visualizado no Gráfico 3. 


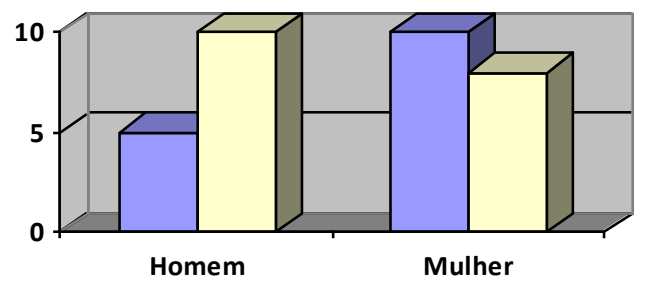

Gráfico 3 - Cruzamento sexo e amostra

Fonte: Da autora

O homem, ao contrário da mulher, ao envelhecer, faz mais uso do alçamento. Observações a esse respeito, contudo, não podem ser conclusivas devido ao desequilíbrio da amostra (sete homens e cinco mulheres).

Podemos concluir que, em relação às variáveis sociais, há um leve crescimento do alçamento com o passar dos anos e que o papel do sexo não é claro. Confirma-se, pelos dados, o caráter incipiente da regra, segundo Bisol (2010).

Já em relação ao contexto precedente, os dados, analisados em conjunto com o total de ocorrências dos dois períodos, mostram algum papel para a vogal /e/ e /o/, segundo a Tabela 2.

Tabela 2 - Contexto Precedente.

\begin{tabular}{l|l|l|l|l|l|l}
\hline & \multicolumn{3}{|c|}{ Vogal /e/ } & \multicolumn{3}{c}{ Vogal /o/ } \\
\hline & $\begin{array}{l}\text { Aplic./ } \\
\text { Total }\end{array}$ & $\%$ & $\begin{array}{l}\text { Peso } \\
\text { Relativo }\end{array}$ & $\begin{array}{l}\text { Aplic./ } \\
\text { Total }\end{array}$ & $\%$ & $\begin{array}{l}\text { Peso } \\
\text { Relativo }\end{array}$ \\
\hline $\begin{array}{l}\text { Labial } \\
\text { pelado, botar) }\end{array}$ & $40 / 406$ & 9,9 & .48 & $54 / 323$ & 16,7 & .54 \\
\hline $\begin{array}{l}\text { Palatal (general, } \\
\text { chover) }\end{array}$ & $17 / 95$ & 17,9 & .81 & $8 / 34$ & 19 & .78 \\
\hline $\begin{array}{l}\text { Coronal (senhor, } \\
\text { solteiro) }\end{array}$ & $43 / 604$ & 7,1 & .45 & $22 / 303$ & 7,3 & .20 \\
\hline $\begin{array}{l}\text { Dorsal (querência, } \\
\text { governo) }\end{array}$ & $1 / 168$ & 0,6 & --- & $76 / 475$ & 16 & .54 \\
\hline
\end{tabular}

Fonte: Da autora.

O alçamento de /e/ e de /o/ parece ser favorecido pela consoante palatal. Entretanto, o número de aplicações é muito baixo para se fazer alguma generalização, assim como há poucos dados para os contextos precedentes dorsal e coronal no que se refere a /e/ e a /o/, respectivamente. 
Os resultados expressos na Tabela 2 parecem estar, em geral, de acordo com os dados das pesquisas de Klunck (2007) e de Marchi e Stein (2007) sobre esse mesmo fenômeno, com amostras de Porto Alegre e de Curitiba, pois também não apontam algum condicionamento claro. Bisol (2010), comparando as amostras desses dois estudos, conclui que, com exceção do papel da dorsal referente ao alçamento de /o/, não há um condicionamento específico. Além disso, a autora observa que os dados entre as duas pesquisas são incongruentes, dada a irregularidade dos resultados.

Os dados desta investigação corroboram as considerações de Bisol (2010). Também se mostram incongruentes com os resultados dessas outras pesquisas em relação ao papel da consoante dorsal sobre a vogal /o/, pois, na Tabela 2, essa variável não se apresenta favorecedora nem desfavorecedora.

A amostra utilizada concentra dados de ocorrências da fala da mesma pessoa em dois intervalos de tempo. Talvez o léxico dessas pessoas não tenha se alterado significativamente, apesar do alçamento ter crescido na maior parte da vida dos indivíduos, segundo o Gráfico 1. Esse dado, de certa forma, auxilia Bisol em sua argumentação de que o alçamento se dá no contexto da palavra e não no do som.

Notam-se palavras comuns nas duas amostras utilizadas, assim como a aplicação do alçamento em paradigmas semelhantes, como é o caso de $\mathrm{s}[\mathrm{i}]$ nhor/s[i]nhora; p[i]queno/p[i]quena/p[i]quenos; c[u]nhecer/c[u]nhece/ c[u]nhecido; c[u]mer/c[u]meram/c[u]mendo. Este resultado também corrobora as conclusões de Bisol (2010) de que se trata de um fenômeno que atua no léxico.

\section{Conclusão}

O alçamento sem motivação aparente em vogais médias pretônicas /e, o/ é um fenômeno antigo e estável no português brasileiro. Questiona-se se é um processo motivado por condicionamento fonético ou lexical. As duas posições encontram certo respaldo quando se observam palavras realizadas com [i, u], em que as vogais dorsais (quebrado, governo) e labiais (pelado, boneca) são precedentes, e as vogais palatais (senhora, sonhar) são seguintes.

No que se refere à variedade falada no sul do País, os resultados de pesquisas realizadas não mostram claramente que se trata de uma regra variável, segundo Bisol (2010), mas sim de um processo difusionista, cujo canal de expansão é o léxico.

Os dados analisados neste trabalho, em que se comparou a fala de doze indivíduos, em dois períodos de tempo, reforçam as considerações de que não existe condicionamento fonético no uso de vogais altas na posição pretônica. Uma análise mais detalhada do léxico do indivíduo talvez possa esclarecer se se trata da aplicação do alçamento em palavras que são 
frequentemente utilizadas pelas pessoas ou se o processo tende a se difundir por palavras diferentes.

\section{REFERÊNCIAS}

BATTISTI, E. Elevação das Vogais Médias Pretônicas em Sílaba Inicial de Vocábulo na Fala Gaúcha. 125p. Dissertação (Mestrado em Letras). Universidade Federal do Rio Grande do Sul. Porto Alegre - RS, 1993.

BISOL, L. Harmonização Vocálica: uma regra variável. 332p. Tese (Doutorado em Letras). Universidade Federal do Rio de Janeiro. Rio de Janeiro - RJ, 1981.

O Alçamento da Pretônica sem Motivação Aparente. In: BISOL, L; COLLISCHONN, G. Português do Sul do Brasil: variação fonológica. Porto Alegre: EDIPUCRS, 2010, p. 63-78.

CALLOU, D.; LEITE, Y. As Vogais Pretônicas no Falar Carioca. Estudos Linguísticos e Literários. Salvador: UFBA, 1986, p. 151-162.

CARDOSO, S. A. As Vogais Médias Pretônicas no Brasil: uma visão diatópica. In: AGUILERA, V. de A. (Org.). Português do Brasil: estudos fonéticos e fonológicos. Londrina: Universidade Estadual de Londrina, 2009.

CASTRO, E. C. de. As Pretônicas na Variedade Mineira Juizforana. 306 p. Dissertação (Mestrado em Letras). Universidade do Rio de Janeiro. Rio de Janeiro - RJ, 1990.

KLUNCK, P. A elevação da pretônica sem motivação aparente. Dissertação (Mestrado em Letras). Pontifícia Universidade Católica do Rio Grande do Sul. Porto Alegre, RS, 2007.

LABOV, W. Sociolinguistic patterns. Philadelphia: University of Pennsylvania Press, 1972. 308, 1981.

Resolving the neogrammarian controversy. Language, n. 57, p. 267-

Principles of Linguistic Change. Internal Factors, v. 1. Oxford: Blackwell, 1994.

MARCHI, F. de; STEIN, R. de C. G. Alçamento de Vogais Médias Pretônicas sem Motivação Aparente em Curitiba. Cadernos de Pesquisa em Linguística. Porto Alegre: EDIPUCRS, v.3, n.1, p.127-137, 2007.

NASCIMENTO SILVA, A. As Pretônicas no Falar Teresinense. Tese (Doutorado em Letras). Pontifícia Universidade Católica do Rio Grande do Sul. Porto Alegre - RS, 2009.

SANKOFF, D. Variable rules. In: AMMON, U.; DITMAR, N.; MATTEIR, K. (Ed.) Sociolinguistics: an international handbook of language and the society. New York: Walter de Gruyter, 1988. p. 984-988.

(org.). Diversity and Diachrony. Amsterdam/Philadelphia: John Benjamins Publishing Company, 1988. 
SILVA, M. B. As Pretônicas no Falar Baiano: a variedade culta de Salvador. Tese (Doutorado em Letras). Universidade Federal do Rio de Janeiro. Rio de Janeiro - RJ, 1989.

VIEGAS, M. do C. Alçamento das Vogais Médias Pretônicas: uma abordagem sociolinguística. Dissertação (Mestrado em Letras). Universidade Federal de Minas Gerais. Minas Gerais - MG, 1987. 